\title{
Organisms, activity, and being: on the substance of process ontology
}

\section{Christopher J. Austin ${ }^{1}$}

Received: 23 May 2019 / Accepted: 4 February 2020 / Published online: 21 February 2020

(C) The Author(s) 2020

\begin{abstract}
According to contemporary 'process ontology', organisms are best conceptualised as spatio-temporally extended entities whose mereological composition is fundamentally contingent and whose essence consists in changeability. In contrast to the Aristotelian precepts of classical 'substance ontology', from the four-dimensional perspective of this framework, the identity of an organism is grounded not in certain collections of privileged properties, or features which it could not fail to possess, but in the succession of diachronic relations by which it persists, or 'perdures' as one entity over time. In this paper, I offer a novel defence of substance ontology by arguing that the coherency and plausibility of the radical reconceptualisation of organisms proffered by process ontology ultimately depends upon its making use of the 'substantial' principles it purports to replace.
\end{abstract}

Keywords Substance $\cdot$ Process ontology $\cdot$ Identity $\cdot$ Organisms $\cdot$ Philosophy of biology

\section{Introduction}

What is an organism? There is at present a prominent dichotomy in the sorts of answers prevalent in the contemporary philosophy of biology literature which correspond to two radically distinct ontologies. The first type of answer endorses a broadly mechanistic ontology wherein organisms are conceptualised as the mereological sums of organised collections of entities bearing certain spatial and causal relations to one another - they are, in other words, specialised sorts of machines. Especially preeminent since the scientific revolution of the seventeenth century, and bolstered by the philosophical and scientific influence of the 'mechanical philosophy' of Hobbes, Gassendi, and Descartes, this ontology of organisms has been by far the one most widely adopted throughout the history of philosophy (Allen 2005). The second type of answer to the

Christopher J. Austin

christopherja@gmail.com

1 Durham University, Durham, UK 
organism question endorses a processual ontology wherein organisms are conceptualised as spatio-temporally extended, causally continuous patterns of activity - they are, in other words, dynamically stabilised processes. Although perhaps primitively traceable to the pre-Socratic Heraclitus, this ontology of organisms' theoretical roots were planted by figures like Whitehead, Bertalanffy, and Waddington during the rise of 'organicism', or 'holism' in nineteenth century experimental embryology (Gilbert and Sarkar 2000; Nicholson and Gawne 2015).

Answers to the organism question which are of the first type currently retain dominance in the literature - a not merely inertial achievement attributable in large part to the various successes of the now thriving 'new mechanism movement' in the philosophy of science (Glennan 2017; Glennan and Illari 2018). However, there has rather recently been a notable resurgence of the second sort of answer by prominent figures in the philosophy of biology under the banner of 'process ontology' (PO) (Dupré and Nicholson 2018). According to its adherents, the organism question itself stands in need of a radical reconceptualisation, and adequately answering it requires a drastic shift in both the "received" mechanistic methodology and ontology. In this paper, I examine and assess PO's distinctive reframing of and answer to the organism question. After explicating the motivations and assumptions underlying PO's reformative effort, I critically evaluate the capability of its proposed ontology to provide a plausible answer to its own unique rendering of the organism question. My claim is that, when subject to sufficient scrutiny, PO's competency in this regard is called into serious question: not only does PO lack the conceptual resources to satisfyingly meet its own challenge, it seemingly has no hope of doing so without substantially borrowing from the ontological framework it supposedly supplants.

\section{Dispelling the myth of substance}

As a conceptual framework for characterising the nature of the biological world, PO has quite a lot going for it: it provides a parsimonious, yet comprehensive and empirically informed metaphysical analysis of organisms. Understanding these theoretical virtues, and thus the philosophical appeal of PO, is most easily achieved by contrasting it - as its proponents are wont to do - with the more familiar framework of 'substance ontology' (SO). According to SO, entities are best conceptualised as essentially static, persisting "things": their being consists in stability over time which they maintain by enduring through various accidental (and fundamentally extrinsic) alterations. That the natural world is populated with 'stable continuants' which remain the same while undergoing change is not only (one presumes) a pre-theoretically "default" ontological perspective, but one deeply engrained in the Western philosophical tradition under the emblem of Aristotelianism. As is well known, in the Aristotelian framework, the category of substance is centre stage - it captures the intrinsic and immutable essence of entities, the very metaphysical mooring which modally "lies beneath" the everchanging facades they merely contingently exhibit. In this way, SO is a decidedly stability-first metaphysics: the set of unchanging properties an entity possesses which function as the modal foundation for its characteristic features ground its continued existence and define - to employ a distinctively peripatetic bit of phrasing - "what it is to be" that entity. 
'Mechanistic' answers to the organism question, the proponents of PO suggest, are firmly rooted in the SO framework as those answers presuppose not only that organisms are "fixed material entities with clearly defined boundaries" which "exist independently of the activities they engage in and of the relations they maintain with other entities", but that their development, activity, and continued persistence consists in the "systematic rearrangement of the pre-existing thing-like entities that compose them". 1 According to the advocates of PO however, these sorts of answers to the organism question are woefully insufficient: they fail to adequately characterise the nature of organisms and, aligned as they are with SO, are necessarily mistaken ab initio. The claim is that conceptualising organisms as specialised sorts of machines fails to capture their most central feature - their diachronically extended and dynamically variable composition. ${ }^{2}$ For unlike mere machines, the continued existence of organisms doesn't depend upon their remaining the same from moment to moment, but upon their continually successive differentiation: far from being essentially "static" entities, organisms persist by means of change - be it metabolic, or morphological (DiFrisco 2018; Nicholson 2018). Because organisms are, in this way, essentially dynamical beings, they cannot be conceptualised as consisting of any particular collection of constituents, nor as confined to any particular temporal cross-section of such collections (Jaeger and Monk 2015; Bapteste and Dupré 2013). They are, in other words, fundamentally four-dimensional entities for whom mereological and morphological stability are derivative, and ultimately ephemeral phenomena - that is, they are processes rather than 'things'.

From the perspective of PO then, those who accept broadly mechanistic answers to the organism question are operating under a particularly powerful illusion - they have bought into the "myth of substance": the belief that organisms possess some stable, unchanging, essential features in which their identities are ontologically grounded (Seibt 1996, 2018). ${ }^{3}$ Like so many mythologies, this is a set of beliefs which, although pervasive, fails to accord with our best understanding of the natural world: organisms, the advocates of PO claim, are not fundamentally static beings, but rather ever-changing, always-in-flux beings whose "essence" consists merely in the diachronic propagation of particular patterns of activity. Thus, as Nicholson (2018: 153), following Rescher (1996), points out, the well-known scholastic adage embodied in the principles of SO that "activity follows from being" (operari sequitur esse) is, in the case of organisms, simply backwards - their 'being' is built from and thus subordinate to their activities.

To the uninitiated, the dispute between SO and PO may appear, as it were, insubstantial, grounded in conceptual nuances which reflect disputes about terminological and heuristic emphases rather than genuine disagreements concerning the ontology of organisms. After all, although both SO and PO characterise themselves as presenting radically distinct methodologies for "carving at the joints" of the biological world, each of them, in the end, merely offer distinct ways of understanding an 'organism' as an 'individual which persists through changes'. Furthermore, although $\mathrm{SO}$ and PO advocates typically disagree on the criteria biological entities must meet in

\footnotetext{
${ }^{1}$ Dupré and Nicholson (2018: 28-29)

${ }^{2}$ I've detailed in depth elsewhere the various theoretical motivations that PO advocates cite in support of this claim - see Austin (2016).

3 This "myth" commits what Whitehead (1925), the philosophical figurehead of contemporary PO, called the 'fallacy of misplaced concreteness'.
} 
order to properly qualify as 'individuals', and in some cases, on whether any collection of criteria is sufficiently capable of capturing a single, ontologically privileged set of such individuals, their respective ontological "inventories" of the biological world more often than not enjoy a significant amount of overlap. ${ }^{4}$ For while it's certainly true that PO tends to be more permissive than SO, and so tends to produce a much larger ontological inventory than its competitor, their respective inventories are rarely radically divergent. Given that the aim of any adequate such inventory is to catalogue those entities which feature in our most successful inductive generalisations about the biological world (Psillos 1999, 2009; Chakravartty 2011; Khalidi 2013), this should come as no surprise. SO and PO will of course disagree about the nature of the entities which belong in their respective inventories, but both are apt to include (for instance) frogs and firs while disallowing 'trout-turkeys' (Lewis 1991), etc.

However, in general, this conciliatory characterisation of the debate between SO and PO is mistaken, and for an important reason. To see why, let us restrict our focus to the intersection comprised of those members of the respective ontological inventories of SO and PO which "overlap" - i.e. those members which both sides of the debate agree warrant sufficient 'projectibility' (Goodman 1954/1979) to be included in any adequate inventory; call this the standard inventory. Why focus on the 'standard inventory'? Because once we have put aside the deep-seated (and presumably irreconcilable) disagreement between SO and PO regarding the scope or extent of the true, or best ontological inventory of the biological world, and focus solely on an inventory upon which both sides (defeasibly) agree, we can adjudicate between SO and PO on an equal evaluative ground, and thus more clearly discern the genuine conceptual differences which might divide them. ${ }^{5}$ And when we do so, such divisions indeed become evident.

For even in the case of "inventory alignment", SO and PO are not, from a metaphysical perspective, truly aligned, as their respective methodologies for deriving that inventory remain radically distinct. For the purposes of evaluation then, the crucial question is: which account possesses the conceptual resources to produce that inventory? As I am here principally interested in the prospects of PO, the question can be rephrased: can the metaphysical framework of PO coherently produce, or adequately account for this catalogue of individuals? In what follows, I argue that it cannot. The set of organisms that the proponents of PO wish to remain on the chopping block after we have "carved at the joints" of the biological world simply cannot be cleaved with the conceptual instruments PO provides. For, as I illustrate below, any answer to PO's

\footnotetext{
${ }^{4}$ The view according to which there is no unique, ontologically privileged foliation of the biological world is a form of ontological pluralism. This view is importantly distinct from taxonomic pluralism, the view according to which our classificatory criterion fundamentally function as interest-relative heuristics which "cross-cut" reality in various incompatible, but equally acceptable/viable ways (Ereshefsky 2001; Dupré 1999, 2002). Taxonomic pluralism is widely accepted among philosophers of biology on both sides of the debate about the nature of organisms, while ontological pluralism remains contentious even among PO advocates.

${ }^{5}$ Of course if one believes, as Dupré (Dupré and Nicholson 2018: 24) evidently does, that PO entails 'ontological pluralism' (which he calls 'promiscuous individualism'), such common ground is more difficult to come by. However, even the "exploded" inventory of an ontological pluralist will have an overlapping intersection with the inventory of the SO advocate. If however, on the other hand, that ontological pluralism is not taken as a particularly permissive flavor of realism, but rather as a kind of ontological nihilism, this paper's dialectic is clearly a non-starter. But as an anti-realist interpretation of ontological pluralism plausibly renders both SO and PO equally inadmissible, I have excluded an in-depth discussion of the matter here.
} 
unique reframing of the organism question which is sufficient to deliver such a set requires employing equipment its toolbox does not contain.

\section{Reframing the organism question}

Answers to the organism question from the perspective of SO are, as suggested in the above section, ones with which most philosophers will be familiar. There is of course wide variation in the specific details of the answers which advocates of a broadly SO perspective have offered throughout the history of philosophy, but they are unified in the sense that, although they differ in their details, each is derived from a similar approach to the question. According to SO, the identity of any particular organism is grounded in its possession of some specific property, or set of properties which it cannot fail to possess and which functions as the modal ground for its characteristic features - its 'essence'. From this perspective then, any adequate answer to "what it is to be" an organism must appeal to some unchangingly stable, modally rich properties the organism in question possesses. As we have seen, from the perspective of $\mathrm{PO}$, attempting to discover or otherwise elucidate the identity of an organism by means of this methodology is an exercise in futility: the properties of most, if not all, of the organisms which populate the natural world are perpetually "in flux" in a way altogether inimical to the modal strictures of 'essentialism' as described above.

If it is, as Plato paraphrased Heraclitus' ontology, 'becoming' which constitutes the very 'being' of organisms, how then does PO propose to answer the organism question $?^{6}$ As its progenitor's paradigm suggests, according to PO an individual organism is akin to a river: flowing forward through space and time in an everchanging pattern of constant activity. In contemporary parlance, an organism on this perspective is thus essentially a four-dimensional entity - a spatio-temporally extended "worm" tracing through a successive series of "temporal slices", each of which represents a specific dimensionally-indexed "snapshot" of material constitution and (spatial) configuration. A well-known and much discussed consequence of conceptualising an entity as fundamentally four-dimensional is that one must correspondingly judge it as not being "wholly present" at every moment it exists: given that such entities are constituted by complexes of temporal parts, their persistence consists in their perdurance, rather than their endurance. ${ }^{7}$ Properly individuating particular organisms in the framework of PO will then naturally focus not on temporal slices, but on slice-series - and thus on specifying the correct relations between slices which unite them into a proper series.

For these reasons, PO must frame the organism question in a rather particular fashion for, as Guay and Pradeu (2015: 318) put it, adopting PO requires that, "the question 'what is X, fundamentally?' is replaced by the question 'how should I follow $\mathrm{X}$ through time?"'. This is because, in keeping with its avowedly anti-SO assumptions,

\footnotetext{
${ }^{6}$ See Plato (1990: 157b): "The verb 'to be' must be totally abolished - though indeed we have been led by habit and ignorance into using it ourselves more than once, even in what we have just been saying. That is wrong, these wise men tell us, nor should we allow the use of such words as 'something', 'of something', or 'mine' 'this' or 'that', or any other name that makes things stand still. We ought, rather, to speak according to nature and refer to things as 'becoming"'.

${ }^{7}$ See Effingham (2012) for an introductory review of this discussion in the contemporary literature.
} 
the identity of an organism - what it is to be that organism - is, according to PO, less about the compositional-cum-structural content of its various slices than the connective character of its series of slices. The most common approach to answering this essentially diachronic rendering of the organism question involves replacing the traditional, synchronic concept of 'identity' simpliciter with that of 'genidentity' (Lewin 1922), a relation which holds between temporally successive and causally continuous events/ states/etc. Because the organism question, from the perspective of PO, concerns processes rather than properties, the relation of genidentity - which presupposes that 'individuals' do not merely persist through, but are rather the products of particular successions of temporal slices, or stages - is taken to be an appropriate apparatus for answering it. Indeed, utilising that relation allows one to individuate essentially diachronically extended entities in a familiar fashion - namely, compositionally: what it is to be a particular organism is, in this framework, to be a four-dimensional "sum of causally continuous stages" (DiFrisco 2018: 91).

Fundamentally then, as the metaphysical precepts of PO dictate that answering the organism question requires specifying the conditions under which slices form sliceseries, the relation of genidentity functions in the PO framework as a principle of unification: it is the metaphysical "glue" with which a succession of synchronically static slices are fused into diachronically dynamic four-dimensionally extended worms i.e. organisms. Importantly, that relation also performs a restrictive function in that role, in that its criterion of connection serves to "rule-out" certain assemblages from forming proper series - only those temporal slices which are "causally continuous" are taken to come together to compose organisms. This function is crucial for PO's constructing its ontological inventory - that is, the one that sufficiently captures the denizens of the living world - as it allows it to avoid having to declare just any temporally successive slices as members of a single process. On the one hand, its advocates don't want the members of their inventory to be - as their 'substantialist' adversaries' are - restricted by synchronic composition in such a way that their identity over time depends upon their continued possession of some particular property, or set of properties (Guay and Pradeu 2015: 318), but on the other hand, their own inventories must also be in some way safeguarded from unwanted inflation by a variety of "mereological monsters".

In light of PO's reframing of the organism question - that is, in its characterisation of identity primarily in terms of persistence - there are two pertinent questions we must ask of it: (1) can the methodology for answering that question required by its metaphysics (as just discussed) deliver a coherent ontology of organisms and, if it can, (2) is the answer it provides complete? My contention is that while (1) can be answered in the affirmative, (2) cannot. To see why this is so, it is instructive to examine PO's positive case for (1). As suggested in the previous section, I think that case is plausible - though it is not entirely straightforward and unproblematic. For as even the staunchest PO advocates recognise, given the myriad subtleties involved in "reconstructing" the denizens of the living world four-dimensionally, making that case compelling requires more than mere genidentity. ${ }^{8}$ This is because, in short, the restrictions on forming slice-

\footnotetext{
${ }^{8}$ In the latest edited volume on the subject featuring PO's most prominent advocates, Nicholson and Dupré's (2018) Everything Flows: Towards a Processual Philosophy of Biology, nearly every paper on the subject of 'identity/individuation' utilises genidentity while augmenting it in novel ways. I explore some of these conceptual embellishments below.
} 
series that relation provides aren't restrictive enough, and so must be in some way supplemented.

It's not difficult to see that utilising genidentity as the sole criterion for the formation of proper slice-series - for individuating organisms qua processes - is apt to deliver strange (and presumably unwanted) results. The ability to encompass the entire varied succession of temporal slices involved in a multifaceted course of ontogenesis - from birth to maturity - in a single process (and so, as a single organism) is certainly a theoretical virtue, but how can mere genidentity coherently demarcate such processes from their progenitors? Though we were perhaps once mereologically entwined in a metaphysically significant fashion (Kingma 2018), I take it that my mother and I do not compose the same, single organism - my being constituted by a series of successive temporal slices that are causally continuous with those which constitute her notwithstanding. Needless to say, implications of this sort become exponentially worrying the more one widens the scope of 'parent process'.

Genidentity's competency in delineating individuals from their causally continuous products is a problem not limited to origin-offspring relations because, as PO advocates are wont to emphasise (Griffith and Stotz 2018), individual organisms are themselves in important ways products of their environment: as attested to by the phenomenon of phenotypic plasticity, the morphogenesis of organisms - and thus the character of their four-dimensional composition - is a process highly coordinated with and substantially controlled by the causal influence of a wide variety of ecological factors (Fusco and Minelli 2010). Although its advocates often positively cite this (and other similar) phenomenon as indicative of the fact that organisms, like processes proper, possess mereologically "fuzzy boundaries" (Henning 2013; Guttinger 2018; Dupré and Nicholson 2018), if PO is to have any hope of reconstructing the 'standard' ontological inventory of the living world it will presumably need to be able to rule-out it counting as individuals the compositional sums of, for instance, local pheremonal milieus and ant embryos.

Supplementing genidentity in the correct way - to deliver the desired results - is, as these simple worries suggest, rather complicated. Adding further principles of restriction to that relation is likely the most promising way forward. As a first pass toward solving the worries regarding individuation which arise in cases of progenitors and plasticity we might, as DiFrisco (2018: 84), following Collier (2004), suggests, add the requirement that in order for a succession of temporal slices to form a proper series (read: compose an individual organism), they must not only be causally continuous with one another - that is, be genidentical - but also causally cohesive in such a way that "the causal interactions among its parts are stronger than the causal interactions between those parts and their environment, which grants it stability against perturbations". In essence, this requirement provides slice-series with a causal boundary, measured by its 'cohesion profile', or the degree to which its members robustly "stick together" over time. ${ }^{9}$ Distinguishing organism from environment is then relatively

\footnotetext{
${ }^{9}$ It's worth noting that the related concept of 'modularity' used in developmental biology to refer those features common to well-delineated/bounded, semi-autonomous systems is also frequently analysed via the relatively high "strength" of the causal interactions among a system's parts; see Wagner et al. (2007) for a comprehensive review of the concept and its contemporary uses.
} 
straightforward: progenitors and plasticity-inducing factors may be (at certain times, and over particular periods) causally continuous with organisms, but aren't tightly-knit, diachronically resilient members of the slice-series which compose them.

While this addition to genidentity is not without merit, it's safe to say that defining a 'cohesion profile' for any organism in an ontology like PO, which places such a central emphasis on the pervasiveness of mereological fluctuation and alteration, may prove problematic. In particular, it doesn't look like individual such profiles are preserved over the same time-scales that one would presume that organisms are. Consider yourself, qua organism: the conditions under which you are robustly integrated into a single entity have necessarily undergone radical revision throughout the process of your development. The resiliency against external perturbations you exhibited, for instance, as a zygote - that is, the degree to which you could then "withstand" disruption to your mereological integrity - is not identical to that which you exhibit now; nor are the strategies once employed against earlier perils now effective in the same way, or to the same degree, etc. If the identity of organisms qua processual slice-series is determined by those series' 'cohesion profiles', it seems that the process of your development - from embryo to adult - will have produced a multiplicity of individual organisms, rather than one. ${ }^{10}$

The worry here is, in short, that using the criterion of coherence won't provide sufficient continuity from slice to slice to render a succession of slices into a properly unified series. For PO - and indeed, any ontology which utilises genidentity to analyse identity - capturing that sort of continuity is of course especially problematic: for that relation, as Dupré and Nicholson (2018: 25) proudly point out, "poses no restrictions on the amount of change that can take place between the properties of a process at different moments in time". ${ }^{11}$ Having cast aside the conceptual resources of $\mathrm{SO}$ and assigned variation to a position of metaphysical priority, PO's options for establishing sufficient continuity among the members of slice-series to secure individuation are limited. In the case of organisms, the most promising way for PO to replace SO's intraslice continuity - the sort had by a series in virtue of each of its slices possessing/being composed of particular properties, or sets of properties - with inter-slice continuity - the sort had by a series in virtue of each of its slices bearing particular relations to one another - is by amending the relation of genidentity with a criterion of construction.

One of the most remarkable facts about organisms is that they are self-building systems: they are, as Kant (2000: 371) put it, "both causes and effects of themselves" a phenomenon now widely known in the biological sciences as autopoiesis (Maturana

\footnotetext{
${ }^{10}$ Given the variability of 'cohesion regimes' exhibited throughout the life of an organism, the only way in which a single, diachronically comprehensive 'cohesion profile' could be said to be exemplified by an entire four-dimensional process is by assigning each specific regime to a particular time-indexed developmental stage, and conceptualising that profile as the mereological sum of such stages; this "meta-profile" strategy is explored in DiFrisco and Mossio (forthcoming). I'm sceptical whether such a strategy is capable of delivering any natural, non-ad hoc results, though I do not have the space here for a full treatment of the matter. I discuss the general implications of and complications for a similar stage-based strategy in the following section.

${ }^{11}$ Dupré and Nicholson (2018: 25) refer to this lack of restriction as an "obvious advantage" of PO over SO. See also DiFrisco (2018: 90): "The main attraction of this view in the present context is that there is virtually no restriction on the variability of properties among the temporal parts themselves, except that they must be able to stand in the appropriate composition relationship".
} 
and Varela 1980; Razeto-Barry 2012). ${ }^{12}$ A system is autopoietic (literally, self-creating) if the generation, organisation, and regulation of its morphological structure is the result of an intrinsic and iteratively constructive process: as such systems, organisms not only build themselves, but build the means by which they build (and re-build) themselves, etc. In contemporary systems biology, it's not uncommon for autopoiesis to be regarded as the distinguishing feature of organisms qua metabolically robust entities (Weber and Varela 2002; Ruiz-Moreno et al. 2004; Cornish-Bowden 2006) or for the concept to be utilised in determining their persistence conditions (Moreno and Mossio 2015; Toepfer 2012; Bich 2016). As inherently diachronic and dynamical, the potential of autopoietic concepts to contribute to a criterion of organismal individuation/identity has not escaped the notice of PO advocates (Meincke 2018; Nicholson 2018; Arnellos 2018).

Amending the rather permissive relation of genidentity with the constructive character of autopoiesis certainly furnishes one with a more restrictive criterion of sliceseries composition: a succession of temporal slices forms a proper series (i.e. an organism) just in case the later slices are causally continuous with and the constructive products of the earlier ones. By shoring up the inter-slice relations which are sufficient for the composition of organisms, the worries about individuation/identity thus far discussed can be dismissed: the aforementioned continuity of 'cohesion' can be recast as the constructive consistency of the self-scaffolding slice-progressions which "carve out" organisms, an autopoietic process in which neither progenitor parts nor plasticity factors properly achieve mereological membership. If, as PO maintains, the organism question is fundamentally a four-dimensional one, tracing the diachronic progression and perdurance of autopoietic processes certainly has the potential to provide empirically informed and philosophically satisfying answers.

\section{The activity of identity}

On the PO framework, the dynamic and diachronic nature of organisms takes centre stage: the metaphysical ground of the identity of organisms - construed, as we have seen, in terms of their persistence conditions - consists not in their retaining any particular property or set of properties, but in the four-dimensional continuation of a particular causal relation. In other words, in line with its rejection of the metaphysical stasis inherent in SO, PO is a system in which identity is determined by activity - it is a specialised sort of autopoietic activity which functions as the connective "glue" among temporal slices which connects those slices into properly unified, singular series - i.e. particular organisms. In line with PO's reframing of the organism question, let us return to our earlier query: can the methodology for answering that question required by its metaphysics deliver a coherent ontology of organisms? Recall that what is being asked here is whether PO has the

\footnotetext{
${ }^{12}$ Although the explication of the autopoietic conception of life is often attributed to Kant, it has ancient origins in the biologically-informed metaphysics of Aristotle, for whom the characteristic causal activities of natural (read: living) entities were best described - metaphorically of course - as instances of a "doctor doctoring himself' (1984: Physics II.8, 119b30-2); see Lennox (2017) for an excellent contemporary review of the main principles of Aristotelian biology and Austin and Marmodoro (2018), where a neo-Aristotelian autopoiesis-based account of the diachronic unity of organisms is developed. For an examination of Kant's metaphysics of living beings in the context of contemporary evolutionary-developmental biology, see Walsh (2006).
} 
conceptual resources to produce a 'standard inventory' of the living world - one which includes, for instance, succulents and snakes, but not trout-turkeys, etc. The answer to that question is, I think, yes: tracing genidentical relations among temporal slices (and their mereological constituents) which are connected by a sufficiently consistent constructive causal chain will allow one to effectively distinguish organisms from their environments, their progenitors, the contributors to their constitution, etc.

The question remains however, as mentioned in the previous section, whether PO's answer to the organism question is complete. Given that it has adopted a methodological approach to answering that question which is centred on persistence, can PO's epistemologically-laden notion of organismal individuation constitute an ontologically robust notion of organismal identity? I contend that it cannot - contra the insistence of Guay and Pradeu (2015: 318), in the case of organisms, the question "what is X, fundamentally?" can't be sufficiently answered by asking "how should I follow X through time?". To see why this is so one only need attempt to apply PO's account of what it is to be a particular organism to particular organisms. Suppose you were on a diving expedition and, spotting the recognisable floating feathery figure of a crinoid, you wonder "what is that?" As a card-carrying process ontologist you remind yourself: what it is to be that organism is to be a diachronically extended, autopoietically genidentical series of spatio-temporally successive mereological compositions. You're satisfied with your philosophical acumen until, after noting how fundamentally plant-like this organism appears as you observe it floating among a particular sprout of kelp, you then wonder "what's the difference between this organism and that one?" With your earlier answer in mind, you quickly realise you've got a problem: there isn't any difference!

But of course there must be, and in short order - recalling the PO principle that interslice continuity is the ground of identity - you search out what separates the two series: while the "connective" causal relations which bind together both four-dimensional series are autopoietic in nature, the difference in the activities of their constructive character renders them distinct - one is heterotrophic, the other autotrophic. That kelp and this crinoid can't have the same identity, given that they have distinct ways of persisting, and thus distinct conditions under which they achieve diachronic stability and avoid mereological dissipation. Having settled the matter sufficiently, you survey the sea floor again searching for your flowery friend and notice a very similarly shaped creature - a starfish. Your admiration of their shared radial symmetry only lasts so long before you again ask yourself "what's the difference between this organism and that other one?" Recognising that the autopoietic relations which unite these two fourdimensionally extended echinoderms both proscribe the same persistence conditions, you resolve to find some further inter-slice relation which one has and the other lacks. ${ }^{13}$

It isn't difficult to see that this search is unlikely to be fruitful, and for an important reason: the fundamental difference between these two organisms isn't grounded in the distinct ways in which their temporal slices form a proper series, but in the character of their respective series' slices. Or, in other words: it's what the slices are and which order they are in that constitutes the identity of an organism, rather than how those

\footnotetext{
${ }^{13}$ One might attempt to distinguish the two by appealing to their distance differential - e.g. this organism is spatio-temporally separated from that one, and the four-dimensional trajectories their respective slice-series traverse are not, and cannot be coextensive. Unique as they may be, contrasting the "spatio-temporal signatures" (Seibt 2018) of these two organisms strikes me as an ultimately unilluminating strategy for discerning the fundamental difference in their respective identities, though I won't argue that here.
} 
slices are held together. The starfish and the crinoid are distinct sorts of organisms not (or, at least, not principally) because the segments of their four-dimensional "worms" are fastened together in different fashions, but because the respective segments of which they are composed are of a different sort: "what it is to be" either one of them is to be these sorts of slices in this sort of arrangement. We might say then that the identity of an organism is better conceptualised as being constituted by the patterned progression of its slice-series - its unique life-cycle. ${ }^{14}$ This more 'holistic' conception of "what it is to be" a particular organism - one that focuses not just on what unites successive slices into series, but on what those series' slice-succession consists in - has been overwhelmingly embraced by PO advocates. ${ }^{15}$ It's easy to see why: grounding the identity of organisms in their life-cycles not only provides a model which neatly illustrates the dynamical nature of their persistence qua process-perdurance, but one which is capable of capturing the unique mereological-cum-morphological characteristics with which they are individually associated.

With the incorporation of the life-cycle concept, I think it's clear that the first question posed at the beginning of this section - whether the metaphysical framework of PO can answer the organism question in a way that is capable of delivering a sufficiently adequate ontological inventory of the living world - should be answered in the affirmative. Armed with an account of process-individuation which separates processes from their progenitors and the activities of environmental influences by restricting slice-series membership to those which belong to an autopoietically generated succession of stages in a particular four-dimensional pattern, we can capture our familiar world of frogs, firs, and foxes while excluding the myriad of mereological monsters that might be conjured up by metaphysicians.

That said, as capable as the empirically-informed and conceptually rich 'life-cycle process' answer to the organism question is at capturing the its ontological inventory of the living world, I maintain that contrary to its proclamations, PO doesn't have the metaphysical tools to properly procure that inventory, and further, that doing so ultimately requires the tool-kit of SO. To put the point more simply: while PO's answer to the organism question is capable of saving the phenomena - of sufficiently cataloguing the natural world by sufficiently distinguishing this organism from that one - it is incapable of explaining the phenomena - of producing that catalogue by its own means. As I illustrate in what follows, PO can only successfully perform that important latter task by appealing to the central principles of SO.

\section{The identity of activity}

According to SO, "what it is to be" an organism is grounded in a privileged collection of unchangingly stable and modally rich properties the organism in question possesses. In

\footnotetext{
${ }^{14}$ Clearly this more 'holistic' conceptualisation accords well with PO's diachronically focused perspective on organismal individuation: "Strictly speaking, it is incorrect to speak of an egg developing into a frog, as the egg is really a temporal part of the developmental trajectory that is the frog. Organisms cannot be separated from their history. What we perceive as an organism (e.g. a frog) at any given moment represents only a cross section, or time slice, in the unfolding of the persistent process it instantiates." (Dupré and Nicholson 2018: 19) ${ }^{15}$ See, for instance, Dupré and Nicholson (2018), DiFrisco (2018), Griffiths and Stotz (2018), and Fabris (2018)
} 
other words, the identity of an organism is determined by (I) a set of properties it could not fail to possess as long as it exists which (II) define and delimit its range of possible developmental trajectories and determine its characteristic mereological-cummorphological features. As we have seen, PO challenges (I) by claiming that the search for such properties must ultimately be in vain in light of the extreme compositional variation exhibited by organisms over diachronic distances: their ability to persist over such distances, PO maintains, critically relies upon their capacity for continual change. Accordingly PO rejects (II) and the associated claim that "activity follows from being/identity": it maintains that an organism's ontogeny is not guided by its possession of a privileged set of properties rather, it is the process of ontogenesis itself that determines which properties an organism possesses (and which, if any, are privileged with persistence or developmentally disallowed). "What it is to be" an organism, according to PO, is to be a life-cycle-process - that is, an autopoietic activity which produces a four-dimensional pattern of characteristic property possession (i.e. these sorts of slices in this sort of arrangement).

This, however, cannot be the end of the story - or, at least, it cannot be a satisfying one - as if we accept PO's account of the identity of organisms, we are yet left with a further, important identity question. That this is so can be illustrated by invoking the 'substitution of identicals': taking on board PO's claim, asking "what is it to be this organism?" ought to be the same as asking "what is it to be this life-cycle-process?" But the answer to the first question - one we've now spelled-out in some detail from the perspective of PO - isn't an answer to the second question. If organisms just are lifecycle-processes, then PO, if it is to present a coherent ontology, had better have the conceptual resources to explain what is it to be a life-cycle process. And of course, on pain of violating its own principles, that explanation had better not appeal to (I) diachronically stable features of that process which it could not lose while remaining the process it is which (II) function as the modal ground of its operative dynamics.

Can PO give a satisfying account of what it is to be a life-cycle-process that doesn't appeal to (I)? Of course, properties that fit the description of (I) are precisely the sort that PO prides itself on having permanently jettisoned, but one might now reasonably wonder whether it can really be rid of them. After all, isn't what it is to be a life-cycle to be a particular set of time-indexed collections of properties - e.g. egg-tadpolemetamorphosis-adult - which cannot be changed (or temporally re-arranged) without loss of identity ? $^{16}$ Moreover, in light of PO's emphasis on holistic, four-dimensional conceptualisations of organisms, do not the mereological strictures of that framework demand that such collections be fundamentally unchangeable? Of course, a fourdimensional "worm" can have different properties at different times in virtue of it being composed of a series of time-indexed stages which are constituted of distinct properties but, irrespective of whether one thinks that constitutes those entities genuinely undergoing change (rather than merely apparent change, or some sort of successive replacement), surely the same thing can't be said for the stages themselves: as merely mereological sums of such stages, the constitution and ordering of those stages are, for any particular "worm", seemingly set in stone. Mutatis mutandis, while it might be misguided to claim that the aforementioned life-cycle-process cannot undergo a change in properties - given that tadpoles have properties adults do not and vice-versa - the claim that it could undergo a change in its stages (qua time-indexed collections of

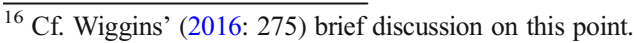


properties) - tadpole-stage earlier than egg-stage, or tadpole-stage without tail-properties, etc. - seems equally mistaken.

If what it is to be an organism is to be a particular life-cycle-process, and what it is to be a life-cycle-process is to be a particular sum of stages, isn't this - in the end - an affirmation of (I)? Such an affirmation, as we have seen, is anathema to PO. But is PO, even after its four-dimensional detour, ultimately committed to (I) $?^{17}$ The most promising way to avoid this result, as far as I can tell, is for the advocate of PO to advance a pair of interrelated claims: (a) the stages which characterise a life-cycle-process are not strictly necessary, but merely exemplary, and (b) the identity of a life-cycle-process (qua activity) isn't grounded in its generative products - i.e. its stages. In support of (a), the PO advocate may point out that, for any particular instance of a life-cycle-process, those stages need not be actually produced, nor produced in precisely the same fashion: not every tadpole-process progresses into an (adult) frog-process, and not every tadpole-process that does will do so in precisely the same way. The textbook tadpoleto-frog pictogram with which we are all familiar may look as if the time-indexed collections of properties that comprise its stages represent de re necessities, but this is misleading - those stages are certainly ontogenetically privileged (in that they are likely to be generated, and generated in certain characteristic fashions), but developmental norms do not necessities make. ${ }^{18}$ Furthermore, turning now to (b), the PO advocate may insist that attempting to ground the identity of a life-cycle-process in such stages is simply mistaken ab initio: just as in the case of organisms more generally, the identity (read: persistence conditions) of a life-cycle-process doesn't consist in the content of its series of stages, but in the continuity of the inter-stage relations which underlie that series' production.

Both (a) and (b) are plausible responses to (I), and ones well aligned with PO's methodology and metaphysic. The former allows PO to make use of the theoretical utility of the 'life-cycle' concept's inclusion of the content and order of stages (as illustrated in the previous section) while retaining the commitment to the fluidity and un-fixedness of organisms, while the latter reflects PO's insistence that organismal identity is grounded in the generative features which function as the causal foundation of such stages. Taking both (a) and (b) seriously suggests what I think is a promising account of life-cycleprocesses: what it is to be a life-cycle-process is to be a set of specific dynamical biases which generatively privilege the production of particular sorts of stages. A natural way to conceptualise what such 'biases' amount to is via the contemporary concept of 'dispositions'. Consider, for instance, the following two facts about dispositions.

Firstly, the causal "directedness" toward the production of particular end-states that characterises dispositions is typically understood as securing a kind of normativity which does not entail necessity: although they tend toward the production of such states, as the infamous cases of 'masks' have shown (Johnston 1992; Bird 1998), they

\footnotetext{
${ }^{17}$ If referring to the set of time-indexed stages of a four-dimensional process as "diachronically stable" strikes the reader as odd, he/she is free to read (I) here in its original phrasing - i.e. "a set of properties which could not fail to be possessed as long as it exists". I thank an anonymous reviewer for drawing my attention to this potential ambiguity.

${ }^{18}$ This thought likely lies behind Griffiths and Stotz (2018: 239) definition of a life-cycle as "a token of a life history strategy", where a 'life history' is taken to be a suitably generalised survival "optimisation" process; my emphasis. See also DiFrisco and Mossio (forthcoming): "the sortals capable of determining boundaries for developments will be complex, specifying a normal or typical series of stages"
} 
only serve as the truthmakers for non-monotonic, "variably strict" conditionals in which those states are consequents (Schrenk 2010). A causal tendency whose generative force is "less than necessity, but more than pure contingency" (Mumford and Anjum 2011) is prima facie precisely the sort of 'dynamical bias' appealed to in the above account of life-cycle-processes. Secondly, the manifestations of dispositions are notoriously context-sensitive in such a way that a single disposition is capable of producing a gradated range of quantitatively and qualitatively distinct end-states in response to a multitude of subtly distinct stimuli. This "multi-track" nature of dispositions (Vetter 2013; Williams 2011) - their tendency to produce 'determinate' variations on certain 'determinable' end-states - clearly accords well with the kind of stagedifferentiation apparent in particular instances of life-cycle-processes of the sort appealed to in PO's above response to (I).

This dispositional account of life-cycle-process identity is, I think, both a theoretically coherent and philosophically compelling way for defenders of PO to avoid an implicit acceptance of the four-dimensional variant of (I). ${ }^{19}$ It is also however one that is, from the perspective of PO, potentially problematic. For although it may have arisen from a rejection of (I), adopting it appears to come at the price of accepting (II), as it is an account which rather plainly entails that the autopoietic activity that characterises a life-cycle-process is the dynamical consequence of, and is thus ontologically dependent upon, a collection of ontogenetic constraints which define and delimit its possible developmental trajectories and determine the characteristic mereological-cummorphological features it produces. ${ }^{20}$ In other words, it entails that the activity of a life-cycle-process "follows from" the nature, or being of that collection: what it (qua process) does depends upon what it (qua collection) is. Its pro-PO theoretical virtues aside, embracing a dispositional account of this kind appears to be a pro tanto endorsement of SO. If, as the above discussion has suggested, the PO-based dialectical discovery of life-cycle-process identity ultimately bottoms out in something like a dispositional account of this sort, is this not a vindication of SO?

There are three ways in which the defender of PO might attempt to avoid the move from accepting a dispositional account of life-cycle-process identity to the validation of SO. The first strategy consists in denying that these generative dispositions truly lie "at the bottom" of such a process; and thus denying that they qualify as "identitydetermining" in the relevant sense. One might accept the claim that such dispositions causally underwrite the processes which produce the typical time-slices/developmental stages characteristic of particular life-cycles, but insist that they themselves - their existence, possession, maintenance, etc. - depend upon the activity of a "deeper", more fundamental process. Following the logic of the response to the stage-based variant of (I) given above, the PO advocate might insist that, for any particular life-cycle, (a*) the processual production of these dispositions is not necessary, but only exemplary, ${ }^{21}$ and

\footnotetext{
${ }^{19}$ I do not claim that it is the only possible way, though I leave it to the defenders of PO to provide others.

${ }^{20}$ Though a full examination of the subject would take the current discussion too far afield, I think the case for the dependence of 'activity' upon 'constraint/bias' appealed to in (II) can be made more generally (and perhaps non-dispositionally) by a close examination of the concept of thermodynamical 'work' in classical dynamics (Hooker 2013; Deacon 2011; Kauffman 2000). For a recent detailed application of that concept in the analysis of ontogenesis, see Moreno and Mossio (2015).

${ }^{21}$ I discuss the issue regarding whether a life-cycle-process might only contingently be characterised by such dispositions in more detail below.
} 
that $\left(b^{*}\right)$ these dispositions are but the (higher-level) products of the activity of a further (lower-level) process.

Its alignment with the general methodological logic of PO notwithstanding, this strategy fails to offer a compelling reason for removing dispositions from their place of primacy but merely "pushes back" the what it is to be a life-cycle-process question for which they were posited in the first place. Even if we were to pursue this strategy, why should we not think (given the preceding discussion) that metaphysically accounting for the identity of a life-cycle-process characterised by $\left(a^{*}\right)$ and $\left(b^{*}\right)$ will lead us - just as it did when we accounted for the identity of a life-cycle-process characterised by (a) and (b) - to an appeal to dispositional properties? Such an accounting might ultimately end in an appeal to some rather unorthodox dispositions - e.g. 'iterated dispositions', which are dispositions for the production and maintenance of further dispositions - but it's difficult to see how employing any strategy which in some fashion makes use of the logic exemplified in (a) and (b) to undermine the identity-grounding role of such properties (and thus, SO) is going to be successful. ${ }^{22}$

The second strategy consists in denying that dispositional facts about developmental bias represent any fundamentally intrinsic features of life-cycle-processes. One might suggest that, contrary to the principles of SO, the dispositions that define life-cycleprocesses are best conceptualised as representing essentially extrinsic, relational facts about those processes. That is to say, it could be argued the modal facts about those processes which such biases represent are less de re than SO supposes: adopting a familiar (and now fairly widely held) counterpart theoretic framework (Lewis 1973) one could hold that facts about an organism's generative proclivities are grounded in its comparative relations to the exhibited morphological histories of other, relevantly similar organisms (its intra-world 'counterparts'), rather than somehow in the 'being' of the organism itself. ${ }^{23}$

Is this extrinsic and relational rendering of the identity of life-cycle-processes plausible? I think not. For accepting it would entail, for example, that the 'butterfly' life-cycle-process' being dynamically biased toward chrysalis stages producing wingsprouting stages is a matter of its bearing similarity relations to a set of other life-cycleprocesses with comparable metamorphic histories. But this seems seriously mistaken: what it is to be a butterfly - its identity, as given by its unique set of generative proclivities - isn't determined by whether and to what extent the 'butterfly process' resembles the life-cycles of other holometabolous organisms. ${ }^{24}$ Rather, the modal features which define the autopoietic activity of the butterfly life-cycle-process represent facts about that very activity: that it cannot, for instance, produce adults whose heads are adorned with antlers isn't due to the fact that some set of relevantly similar

\footnotetext{
22 On 'iterated dispositions', see Vetter (2015).

${ }^{23}$ I note in passing that it may be that a counterpart-theoretic framework is the most plausible way for the sort of four-dimensionalism often endorsed by the advocates of PO to account for de re modality - see Van Inwagen (1990) and Sider (2001).

${ }^{24}$ The claim here (and below) is only that the view according to which the generative proclivities characteristic to a life-cycle can be grounded in the external relations it holds to other similar life-cycles is mistaken. This is importantly distinct from the claim that the cladistic classification of a life-cycle (qua 'butterfly', for instance) cannot be similarly grounded. My claim is not, to utilise a well-worn distinction from Mayr (1961), that facts about the cladistic-identity of life-cycles cannot be 'ultimately' grounded (e.g. in facts concerning phylogenetic relations), but only that the relevant modal facts about life-cycles currently under consideration (i.e. those concerning their dynamical biasing of morphogenesis) are most plausibly 'proximately' grounded.
} 
activities have always failed to do so, but to the fact that the production of antlers is dynamically "forbidden" by the intrinsic character of that activity itself. ${ }^{25}$ It is these latter sort of facts which serve as the foundation for the construction of the resemblance classes between which comparison relations of the first sort hold, and the dependence ontologically, if not also epistemologically - is decidedly one-way. ${ }^{26}$

The third strategy the defender of PO might pursue is to accept that the identities of life-cycle-processes consist in collections of intrinsic developmental capacities but deny that the identity of any particular life-cycle-process necessarily consists in any specific such collection. One might contend that, contrary to the principles of SO, those collections are fundamentally just as subject to the contingencies of the Hericlitian flux as the typical sorts of properties which life-cycle-processes possess. After all, it seems perfectly consistent to recognise that dispositions occupy a privileged place in the individuation of life-cycle-processes in virtue of the unique causal-cum-modal role they play in the autopoietic activities of organismal morphogenesis and yet deny that the identity of every such process consists in a certain collection of dispositions which could not possibly have been different.

On closer inspection however, I think the viability of this strategy should be called into serious question. Is it plausible to hold, for instance, that this turtle could lose (or simply lack) the propensity to grow (and generatively maintain, etc.) a hard shell without it ceasing to exist qua turtle? Note that we're not inquiring whether this organism might not grow a shell - that is, whether its disposition to do so (given the occurrence of appropriate developmental and environmental 'stimulus conditions') might remain unmanifested: that this teratological state of affairs is possible is, I take it, fairly uncontroversial. Note also that we're not inquiring here whether this organism might come to lose the propensity to grow a shell: as PO advocates are wont to emphasise, no entity, natural or artificial, is exempt from the vagaries of contingency. Rather, what we're asking is whether this organism could lose that propensity while remaining a turtle - this is the pertinent question to ask if what we're interested in is "what it is to be" a turtle-life-cycle. In other words, it is not the necessity of this turtle's being generatively disposed in such a way that we are interested in per se, but rather the necessity of this organism being so disposed if it is turtle: in the jargon of analytic metaphysics, we're interested not in whether this organism is so disposed in every possible world in which it exists, but whether, in every possible world in which this organism exists and is a turtle it is so disposed. ${ }^{27}$

One could certainly imagine the defender of PO opting for a negative answer here in line with their previous dialectical strategy. To see how plausible this move is, let us consider the way in which that strategy has been employed in our discussion thus far.

\footnotetext{
${ }^{25}$ Whether one finds this claim philosophically compelling will likely depend upon how persuaded one is by Kripke's (1980) so-called Humphrey Objection to Lewis' (1986) 'modal realism', or the position one takes in the debate about the role of 'laws of nature' in causation (Mumford 2004). Whether one finds this claim scientifically compelling, on the other hand, will likely depend upon one's views on the so-called 'inherency' of morphological variation in ontogenesis - see Newman (2018) for a recent discussion of this concept in the context of evolutionary-developmental biology.

${ }^{26}$ Of course, one could agree that the relevant dependence here is one-way, but insist that it goes in the other direction. Although this is a possible avenue of response, and following it would certainly dilute the dialectical force of the intuition just outlined, it is also a perilous one - that way lies 'resemblance nominalism' (Rodriguez-Pereyra 2002).

27 This is essentially an appeal to a form of so-called 'weak necessity', as introduced by Kripke (1980).
} 
We began by noting that, in rejecting the crude form of 'composition is identity' with which they associate with SO, the PO advocate claims that the diachronic identity of organisms is grounded not in their mereological make-up, but in the persistence of a single life-cycle-process whose 'stages' are compositionally non-identical over time. Once we made the move to a four-dimensional perspective, we then asked: isn't the identity of a life-cycle-process grounded in its stage-composition? No, said the defender of PO: (a) such stages are merely exemplary, not necessary, and (b) the identity of a life-cycle-process is grounded in the generative proclivities which causally undergird the production of its stages.

What we're now asking is: isn't the identity of a life-cycle-process grounded in its dispositional-composition? Here the defender of PO may wish to employ the same strategy, insisting that these compositional elements too are subject to the all-pervasive Hericlitian flux and are thus fundamentally inessential to the identity of a life-cycleprocess - but then, what are we left with? In what does the identity of a life-cycleprocess consist? Not in its mereological make-up over time, not in its time-indexed collection of developmental stages, not in the generative proclivities which causally underwrite the diachronic production of its stages - but what? At this point, what once seemed a promising strategy for resisting SO has I think run its course. To my mind, an affirmative answer to the question we're now interested in is not only more conceptually attractive, but far more plausible.

Thus I maintain that what it is to be a particular life-cycle-process just is to be a particular collection of developmental propensities. For to suggest otherwise, and to hold that any particular life-cycle-process is characterised by a specific set of such potentialities merely contingently, is tantamount to affirming that the collection of ontogenetic constraints which define and delimit an organisms possible developmental trajectories and determine its characteristic mereological-cum-morphological features could change while that organism remains (an instance of) the same life-cycle-process. But plausibly, in the case of such processes, differences in the specific set of dynamical biases which generatively privilege the production of particular sorts of stages entail ontological distinctness: the turtle-life-cycle-process, for instance, is not the butterflylife-cycle-process precisely because the two form non-overlapping sets of developmental potentialities. ${ }^{28}$ Importantly, accepting this claim doesn't amount to the rejection of the aforementioned pro-PO points (a) and (b), though it does suggest a novel interpretation of their ontological implications.

To put the point picturesquely we might say that what it is for an organism to be an instance of a particular life-cycle-process isn't - as (a) and (b) indicate - for it to be a specific four-dimensional worm (comprised of these specific stages at these specific times, etc.), but rather for it to be a particular set of four-dimensional "worm-ways" - a system of tunnels through which it might possibly worm, each of which represents a potential developmental trajectory that organism might follow. Defining a life-cycle-

\footnotetext{
${ }^{28}$ If there were empirical evidence of this sort of overlap - if out of turtle eggs sometimes sprung postchrysalitic winged arthropods - I suspect that we'd have rightly readjusted our ontological inventory. Interestingly, we owe the modern-day availability of sushi to just this sort of adjustment taking place. When Kathleen Drew (1949) showed that, despite all appearances to the contrary, the seaweed species Porphyra umbiliclis and the alga species Conchocelis are but two stages of single organismal life-cycle, Japanese researches realised the same is true of their local seaweed species Pyropia, and the controlled and large-scale production of the seaweed used in sushi became feasible.
} 
process via a set of worm-ways respects the intuition that organisms which are instances of those processes are restricted in the content and order of their stages as any worm of this sort must travel through these tunnels going in these directions but are nevertheless fluid and unfixed in the minute particularities of how those stages are reached, or realised (if they are) - as there are many possible pathways through these tunnels which any particular worm of this sort might traverse. Tunnel-talk here is of course metaphorical, but it illustrates the metaphysical claim quite well: if what it is to be a life-cycle-process is, as I am claim, to be a specific set of dynamical biases or generative proclivities, one can conceptualise the ontological import of an organism realising a particular life-cycle as that set of dispositions "carving-out" those tunnels, giving both structure and direction to its processual perdurance qua an organism of this sort. If this general picture represents reality, the rationale behind declaring the members of such a set necessary is clear - alterations in that set constitute changes whose consequences are of the most far-reaching and fundamental kind.

\section{Conclusion}

As we have seen, the PO-based dialectical discovery of what it is to be an organism leads one to the life-cycle concept, as properly accounting for the persistence-based identity of organisms and sufficiently capturing the a 'standard' ontological inventory of the biological world requires more than mere genidentity. I have argued that the most plausible account of the identity of a life-cycle-process is a dispositional one, as the general features of this sort of account best align with the theoretical commitments of PO (via (a) and (b) above). However, as the discussion of the previous section has indicated, in order for PO to adopt and take advantage of the conceptual resources of such an account it must, in the final analysis, appeal to the central principles of SO (via (I) and (II) above).

For on a dispositional account, the identity of a life-cycle-process consists in (I) a set of diachronically stable features of that process which it could not lose while remaining the process it is which (II) function as the modal ground of its operative dynamics (and thus the exhibition of its characteristic properties). Furthermore, it's easy to see that adopting this sort of dispositional account rather straightforwardly requires the rejection of a fundamental postulate of PO - that "being follows from activity". For according to that account the identity, or being of the four-dimensional property patterning of an organism doesn't follow from the activity which produces that pattern: rather, because the identity of a life-cycle-process consists in its set of developmental propensities (rather than its actually exhibited or characteristically exhibited stages), and its autopoietic activity (in any particular instance) is itself an expression of those propensities (however flawed or unique that expression may be), the activity of an organism must follow from its identity, or being (via its realised life-cycle/set of developmental propensities); on this account, in other words, "operari sequitur esse".

In sum then, what the discussion of this paper has illustrated is that PO lacks the conceptual resources to satisfyingly answer its own unique reframing of the organism question. In order to produce its novel answer it must, in the end, borrow from the ontological framework of SO. Ultimately, as I have argued, procuring a plausible persistence-based account of organisms qua processes requires conceptualising 
organism-processes as instances of life-cycle-processes, and the identity of these processes can't be constructed from the merely contingent connections which bind a series of slices/stages, but must consist in a set of capacities whose dynamical competency is the causal-cum-modal ground of the characteristic activities which produce such series. Thus, if my arguments in this paper have gone through, one could say that if there is anything "of substance" in process-based analyses of organisms it is, rather fittingly, because of substance.

Acknowledgements This work was undertaken as part of the Leverhulme Trust Research Project PartWhole Relations within the Fundamental Potentialities in Nature (D/Ref: 75647), directed by Anna Marmodoro at Durham University. My thanks to the members of the Metaphysics of Biology: Framing the Interactions between Metaphysics and Molecular, Developmental, and Evolutionary Biology research project, funded by the Ministerio de Ciencia, Innovación y Universidades (Ref: FFI2017-87193-P) at the University of Murcia, for their helpful feedback and support.

Open Access This article is licensed under a Creative Commons Attribution 4.0 International License, which permits use, sharing, adaptation, distribution and reproduction in any medium or format, as long as you give appropriate credit to the original author(s) and the source, provide a link to the Creative Commons licence, and indicate if changes were made. The images or other third party material in this article are included in the article's Creative Commons licence, unless indicated otherwise in a credit line to the material. If material is not included in the article's Creative Commons licence and your intended use is not permitted by statutory regulation or exceeds the permitted use, you will need to obtain permission directly from the copyright holder. To view a copy of this licence, visit http://creativecommons.org/licenses/by/4.0/.

\section{References}

Allen, G. (2005). Mechanism, Vitalism and Organicism in late nineteenth and twentieth-century biology: The importance of historical context. Studies in the History and Philosophy of Biological and Biomedical Sciences, 36(2), 261-283.

Aristotle. (1984). The Complete Works of Aristotle (Vol. I \& II). (J. Barnes, Trans.) Princeton: Princeton University Press.

Arnellos, A. (2018). From organizations of process to organisms and other biological individuals. In D. Nicholson \& J. Dupré (Eds.), Everything flows: Towards a Processual philosophy of biology (pp. 199221). Oxford: Oxford University Press.

Austin, C.J. (2016). The ontology of organisms: Mechanistic modules or patterned processes? Biology \& Philosophy, 31(5), 639-662.

Austin, C.J. \& Marmodoro, A. (2018). Structural Powers and the homeodynamic unity of organisms. In W.M.R. Simpson, R.C. Koons, \& N.J. Teh (Eds.), Neo-Aristotelian perspectives on contemporary science (pp. 169-184). London: Routledge.

Bapteste, E., \& Dupré, J. (2013). Towards a Processual microbial ontology. Biology and Philosophy, 28(2), $379-404$.

Bich, L. (2016). Systems and organizations: Theoretical tools, conceptual distinctions and epistemological implications. In G. Minati, M. Ambram, \& E. Pessa (Eds.), Towards a post-Bertalanffy systematics (pp. 203-209). New York: Springer.

Bird, A. (1998). Dispositions and antidotes. The Philosophical Quarterly, 48(191), 227-234.

Chakravartty, A. (2011). Scientific realism and ontological relativity. The Monist, 94(2), 157-180.

Collier, J. (2004). Self-organization, individuation and identity. Revue Internationale de Philosophie, 2, 151-172.

Cornish-Bowden, A. (2006). Putting the systems Back into systems biology. Perspectives in Biology and Medicine, 49(4), 475-489.

Deacon, T. (2011). Incomplete nature: How mind emerged from matter. Norton.

DiFrisco, J. (2018). Biological processes: Criteria of identity and persistence. In D. Nicholson \& J. Dupré (Eds.), Everything flows: Towards a Processual philosophy of biology (pp. 76-95). Oxford: Oxford University Press. 
DiFrisco, J., \& Mossio, M. (forthcoming). Diachronic identity in complex life cycles: An organizational perspective. In a. Meincke, \& J. Dupré (Eds.), Biological Identity: Perspectives from Metaphysics and the Philosophy of Biology. London: Routledge.

Drew, K. (1949). Conchocelis-phase in the life-history of Porphyra umbilicalis (L.) Kütz. Nature, 164, 748749.

Dupré, J. (1999). On the impossibility of a monistic account of species. In R. Wilson (Ed.), Species: New interdisciplinary essays (pp. 3-22). Cambridge: The MIT Press.

Dupré, J. (2002). Humans and other animals. Oxford: Clarendon Press.

Dupré, J., \& Nicholson, D. (2018). A manifesto for a Processual philosophy of biology. In D. Nicholson \& J. Dupré (Eds.), Everything flows: Towards a Processual philosophy of biology (pp. 3-45). Oxford: Oxford University Press.

Effingham, N. (2012). Endurance and Perdurance. In N. Manson \& R. Barnard (Eds.), The continuum companion to metaphysics (pp. 170-197). London: Bloomsbury.

Ereshefsky, M. (2001). The poverty of the Linnaean hierarchy: A philosophical study of biological taxonomy. Cambridge: Cambridge University Press.

Fabris, F. (2018). Waddington's Processual epigenetics and the debate over cryptic variability. In D. Nicholson \& J. Dupré (Eds.), Everything flows: Towards a Processual philosophy of biology (pp. 246-263). Oxford: Oxford University Press.

Fusco, G., \& Minelli, A. (2010). Phenotypic plasticity in development and evolution: Facts and concepts. Philosophical Transactions of the Royal Society B, 365(1540), 547-556.

Gilbert, S., \& Sarkar, S. (2000). Embracing complexity: Organicism for the 21 st century. Developmental Dynamics, 1-9.

Glennan, S. (2017). The new mechanical philosophy. Oxford: Oxford University Press.

Glennan, S., \& Illari, P. (2018). The Routledge handbook of mechanisms and mechanical philosophy. New York: Routledge.

Goodman, N. (1954/1979). Fact, fiction, and forecast. Cambridge: Harvard University Pres.

Griffiths, P., \& Stotz, K. (2018). Developmental systems theory as a process theory. In D. Nicholson \& J. Dupré (Eds.), Everything flows: Towards a Processual philosophy of biology (pp. 225-245). Oxford: Oxford University Press.

Guay, A., \& Pradeu, T. (2015). To be continued: The Genidentity of physical and biological processes. In A. Guay \& T. Pradeu (Eds.), Individuals across the sciences (pp. 317-347). New York: Oxford University Press.

Guttinger, S. (2018). A process ontology for macromolecular biology. In D. Nicholson \& J. Dupré (Eds.), Everything flows: Towards a Processual philosophy of biology (pp. 303-320). Oxford: Oxford University Press.

Henning, B. (2013). Of termites and men. In B. Henning \& A. Scarfe (Eds.), Beyond mechanism: Putting life Back into biology (pp. 233-248). Plymouth: Lexington Books.

Hooker, C. (2013). On the import of constraints in complex dynamical systems. Foundations of Science, 18(4), 757-780.

Jaeger, J., \& Monk, N. (2015). Everything flows: A process perspective on life. EMBO Reports, 16(9), 1064 1067.

Johnston, M. (1992). How to speak of the colors. Philosophical Studies, 221-263.

Kant, I. (2000). Critique of the Power of Judgment. (P. Guyer, \& E. Matthew, trans.) Cambridge: Cambridge University press (first published 1973).

Kauffman, S. (2000). Investigations. Oxford: Oxford University Press.

Khalidi, M. (2013). Natural categories and human kinds. Cambridge: Cambridge University Press.

Kingma, E. (2018). Lady parts: The metaphysics of pregnancy. Royal Institute of Philosophy Supplement(82), $165-187$.

Kripke, S. (1980). Naming and necessity. Harvard University Press.

Lennox, J. (2017). An Aristotelian philosophy of biology: Form, function and development. Acta Philosophica, 26(1), 33-52.

Lewin, K. (1922). Der Begriff der Genese in Physik, Biologie und Entwicklungsgeschichte: Eine Untersuchung zur vergleichenden Wissenschaftslehre. Berlin: Bornträger/Springer.

Lewis, D. (1973). Counterfactuals. Oxford: Blackwell Publishers.

Lewis, D. (1986). On the plurality of worlds. Oxford: Basil Blackwell.

Lewis, D. (1991). Parts of classes. Oxford: Basil Blackwell.

Maturana, H., \& Varela, F. (1980). Autopoiesis and cognition: The realization of the living. Boston: D. Reidel. Mayr, E. (1961). Cause and effect in biology. Science, 134(3489), 1501-1506. 
Meincke, A. S. (2018). Persons as biological processes: A bio-Processual way out of the personal identity dilemma. In D. Nicholson \& J. Dupré (Eds.), Everything flows: Towards a Processual philosophy of biology (pp. 357-378). Oxford: Oxford University Press.

Moreno, A., \& Mossio, M. (2015). Biological Autonomy. Dordecht: Springer.

Mumford, S. (2004). Laws in nature. London: Routledge.

Mumford, S., \& Anjum, R. (2011). Getting causes from powers. Oxford: Oxford University Press.

Newman, S. (2018). Inherency. In L. Nuño de la Rosa \& G. Müller (Eds.), Evolutionary developmental biology: A Refence guide. New York: Springer.

Nicholson, D. (2018). Reconceptualizing the organism: From complex machine to flowing stream. In D. Nicholson \& J. Dupré (Eds.), Everything flows: Towards a Processual philosophy of biology (pp. 139166). Oxford: Oxford University Press.

Nicholson, D., \& Dupré, J. (Eds.). (2018). Everything flows: Towards a Processual philosophy of biology. Oxford: Oxford University Press.

Nicholson, D., \& Gawne, R. (2015). Neither logical empiricism nor Vitalism, but Organicism: What the philosophy of biology was. History and Philosophy of the Life Sciences, 37(4), 345-381.

Plato. (1990). The Theaetetus of Plato. (M. Burnyeat, Ed., \& M. Levett, Trans.) Indianapolis: Hackett Publishing Company.

Psillos, S. (1999). Scientific realism: How science tracks the truth. London: Routledge.

Psillos, S. (2009). Knowing the structure of nature: Essays on realism and explanation. New York: Palgrave MacMillan.

Razeto-Barry, P. (2012). Autopoiesis 40 years later: A review and a reformulation. Origins of Life and Evolution of Biospheres, 42(6), 543-567.

Rescher, N. (1996). Process metaphysics: An introduction to process philosophy. Albany: SUNY Press.

Rodriguez-Pereyra, G. (2002). Resemblance nominalism: A solution to the problem of universals. Oxford: Oxford University Press.

Ruiz-Moreno, K., Pereto, J., \& Moreno, A. (2004). A universal definition of life: Autonomy and open-ended evolution. Origins of Life and Evolution of the Biosphere, 34(3), 323-346.

Schrenk, M. (2010). The powerlessness of necessity. Nous, 44(4), 725-739.

Seibt, J. (1996). The myth of substance and the fallacy of misplaced concreteness. Acta Analytica, 15, 119139.

Seibt, J. (2018). Ontological tools for the process turn in biology: Some basic notions of general process theory. In D. Nicholson \& J. Dupré (Eds.), Everything flows: Towards a Processual philosophy of biology (pp. 113-136). Oxford: Oxford University Press.

Sider, T. (2001). Four-Dimensionalism: An ontology of persistence and time. Oxford: Oxford University Press.

Toepfer, G. (2012). Teleology and its constitutive role for biology as the science of organized Systems in Nature. Studies in History and Philosophy of Biological and Biomedical Sciences, 43(1), 113-119.

van Inwagen, P. (1990). Material Beings. Ithaca: Cornell University Press.

Vetter, B. (2013). Multi-track dispositions. The Philosophical Quarterly, 63, 330-352.

Vetter, B. (2015). Potentiality: From dispositions to modality. Oxford: Oxford University Press.

Wagner, G., Pavlicev, M., \& Cheverud, J. (2007). The road to modularity. Nature Reviews Genetics(8), 921931.

Walsh, D. (2006). Organisms as natural purposes: The contemporary evolutionary perspective. Studies in History and Philosophy of Science Part C: Studies in History and Philosophy of Biological and Biomedical Sciences, 37(4), 771-791.

Weber, A., \& Varela, F. (2002). Life after Kant: Natural purposes and the Autopoietic foundations of biological individuality. Phenomenology and the Cognitive Sciences, 1(2), 97-125.

Whitehead, A. N. (1925). Science and the modern world. Cambridge: Cambridge University Press.

Wiggins, D. (2016). Activity, process, continuant, substance, organism. Philosophy, 91(2), 269-280.

Williams, N. E. (2011). Putting powers Back on multi-track. Philosophia, 39(3), 581-595.

Publisher's note Springer Nature remains neutral with regard to jurisdictional claims in published maps and institutional affiliations. 